\title{
YABBY3-Orthologous Genes in Wild Tomato Species: Structure, Variability, and Expression
}

\author{
M. A. Filyushin ${ }^{1}$, M. A. Slugina', ${ }^{1,2}$ A. V. Shchennikova', E. Z. Kochieva ${ }^{1,2}$ \\ 'Federal State Institution «Federal Research Centre «Fundamentals of Biotechnology» of the \\ Russian Academy of Sciences», Leninsky pr. 33, bldg. 2, Moscow, 119071, Russia \\ ${ }^{2}$ Department of Biotechnology, Faculty of Biology, Moscow State University, Leninskie Gory 1, \\ bldg. 12, Moscow, 119991, Russia \\ *E-mail: michel7753@mail.ru \\ Received: April 24, 2017; in final form October 17, 2017 \\ Copyright @ 2017 Park-media, Ltd. This is an open access article distributed under the Creative Commons Attribution License, which permits \\ unrestricted use, distribution, and reproduction in any medium, provided the original work is properly cited.
}

\begin{abstract}
Evolution of the genes encoding YABBY transcription factors is believed to be one of the key reasons for flat leaf emergence from the radially symmetrical stem and gynoecium diversity. $Y A B B Y$ genes determine the identity of the abaxial surface of all aboveground lateral organs in seed plants. In the present study, complete sequences of $Y A B B Y 3$-orthologous genes were identified and characterized in 13 accessions of cultivated and wild tomato species with diverse morphophysiology of leaves, flowers, and fruits. The obtained gene sequences showed high homology (95-99\%) and an identical exon-intron structure with the known $S$. lycopersicum YAB$B Y 3$ gene, and they contained sequences that encode the conserved HMG-like YABBY and Cys2Cys2-zinc-finger domains. In total, in the analyzed $Y A B B Y 3$ genes, 317 variable sites were found, wherein 8 of 24 exon-specific SNPs were nonsynonymous. In the vegetative and reproductive organs of red-fruited and green-fruited tomato species, YABBY 3 gene expression was similar to that in $S$. pimpinellifolium described earlier, but it demonstrated interspecies differences at the leaf-, bud- and flower-specific expression levels.

KEYWORDS YABBY3, polymorphism, qRT-PCR, Solanum section Lycopersicon, adaxial-abaxial asymmetry. ABBREVIATIONS CRC - CRABS CLAW; INO - INNER NO OUTER; FIL - FILAMENTOUS FLOWER; qRT-PCR quantitative real-time PCR.
\end{abstract}

\section{INTRODUCTION}

Plant growth and development processes are controlled by transcription factors, whose evolution is one of the major causes of morphological diversity in the plant kingdom [1-4]. The origin of the flower and reproductive organs is believed to be related to the duplication and changes in MADS-box transcription factor genes $[5,6]$. At the same time, flat leaf emergence from the radially symmetrical stem, as well as gynoecium diversity, is considered to be a consequence of YABBY transcription factor genes evolution [7]. The presence of these genes in angiosperm and gymnosperm plants and their absence in moss and lycopodium [8-10] suggest that $Y A B B Y$ genes originate from one or two predecessors in the last common ancestor of seed plants [10-12]. Diversification of YABBY genes led to the occurrence of individual family members with unique roles in leaf, carpel, and ovule development $[8,11,13,14]$, including the YABBY 2 and YABBY 5 genes, which were presumably involved in the evolutionary divergency of the pistil stalk and stamen filament morphology $[15,16]$. Other
YABBY gene families, INNER NO OUTER (INO) and CRABS CLAW (CRC), apparently developed in parallel with the evolution of the carpel and ovule during leaflike reproductive sporophyll modification [11, 17].

In dicots and monocots, YABBY genes play similar roles in leaf and leaf-like organs development, specifying their abaxial-adaxial asymmetry and lamina growth, as well as leaf boundaries [4, 10, 18]. Additionally, $Y A B B Y$ genes are involved in the formation of such flower organs as nectaries, carpels, etc. [19-21]. To date, the functions of certain YABBY proteins have only been described in the model plant Arabidopsis thaliana. Thus, it has been shown that YABBY1 (syn. FILAMENTOUS FLOWER, FIL), YABBY3, and YABBY5, along with other components of the transcription complex, support the identity of abaxial leaf surface cells and are also involved in the initiation of embryonic shoot apical meristem and its postembryonal maintenance [22]. Activation of a certain YABBY gene expression in the nectaries and carpels involves MADS-domain proteins [23]. In turn, YABBY1, togeth- 
Table 1. The cultivated and wild tomato species used in the present study

\begin{tabular}{|c|c|c|c|}
\hline Species/subspecies/cultivar & VIR Ref. No & Crossing system & $\begin{array}{c}\text { Color of the ripe } \\
\text { fruit }\end{array}$ \\
\hline S. cheesmaniae (Riley) Fosberg & 3969 & self-compatible & Red \\
\hline S. galapagense Darwin \& Peralta & 3970 & self-compatible & Red \\
\hline S. lycopersicum var. humboldtii (Willd.) Dunal & 2912 & self-compatible & Red \\
\hline S. lycopersicum L., cv. Silvestre recordo & 1580 & self-compatible & Red \\
\hline S. pimpinellifolium var. racemigerum (Lange) Brezhnev & 1018 & self-compatible & Red \\
\hline S. chmielewskii (Rick, Kesicki, Fobes \& Holle) Spooner, & 13725 & self-compatible & Green \\
\hline Anderson \& Jansen & 5033 & self-compatible & Green \\
\hline S. neorickii Spooner, Anderson \& Jansen & 13958 & self-incompatible & Green \\
\hline S. arcanum Peralta & 4300 & self-incompatible & Green \\
\hline S. chilense ( Dunal) Reiche & 4367 & self-incompatible & Green \\
\hline S. corneliomulleri Macbr. & 13964 & self-incompatible & Green \\
\hline S. habrochaites Knapp \& Spooner & 4361 & self-incompatible & Green \\
\hline S. peruvianum L. & 3966 & self-incompatible & Green \\
\hline
\end{tabular}

er with other transcription factors, controls the spatial activity of MADS-box genes and, thus, is involved in floral organ primordia initiation in the correct position and number, determining the corresponding cell's fate [24-26].

YABBY genes encode small proteins (180-250 amino acid residues) containing two conserved domains [27, 28]. The $\mathrm{N}$-terminal part of the protein includes the $\mathrm{Cy}-$ s2Cys2-zinc-finger motif, and the $\mathrm{C}$-terminus includes the YABBY domain.

In plant genomes, the $Y A B B Y$ genes number differs. In $A$. thaliana, six $Y A B B Y$ genes were found; four of them (YABBY1, YABBY2, YABBY3, and YABBY5) are mainly expressed in leaves and leaf-like organs (cotyledons, sepals, petals, stamens, and carpels), while the other two (CRC and INO) are expressed in some parts of floral reproductive organs [10, 23, 27]. Eight genes were identified in rice Oryza sativa; moreover, each $O s Y A B B Y 2$ and $O s Y A B B Y 7$ has two alternatively spliced transcripts [29].

Nine $Y A B B Y$ genes (YABBY1, YABBY2, YABBY3, YABBY $5 a$, YABBY $5 b, C R C a, C R C b, F A S$, and INO) were identified in cultivated tomato (Solanum lycopersicum), which is one of the major vegetable crops [30, 31]. S. lycopersicum, along with 12 wild related species, comprises the Lycopersicon section of the Solanum genus [32]. Tomato species widely vary in their morphophysiological characteristics, including leaf and flower morphology. Depending on the mating system structure, tomatoes are divided into self-compatible and self-incompatible species. The latter are characterized by high polymorphism, large flowers, and exerted stigma [32]. It is known that the plant reproductive system, which depends on the flower's morphophysiology, as well as the differences in the leaf structure, can result from the different activities of YABBY transcription factors [7]. First and foremost, this relates to YABBY1/ YABBY3 proteins, which are expressed in almost all asymmetric aboveground plant organs.

The present study was focused on the identification of YABBY3-orthologous genes in wild tomato species and an evaluation of their polymorphism. To date, complete YABBY3 sequences are determined only for two tomato species: $S$. lycopersicum and $S$. pennellii, and YABBY3 expression patterns were characterized only in $S$. lycopersicum [31] and S. pimpinellifolium [30]. Therefore, the present results, based on an analysis of a large number of tomato species, will contribute to our knowledge of $Y A B B Y$ genes and their possible functions.

\section{EXPERIMENTAL}

A set of 13 accessions of 11 tomato species from the collection of the All-Russian Institute of Plant Genetic Resources n.a. N.I. Vavilov (VIR) was selected for this study. The analyzed species differed both in the mating system and fruit morphology (Table 1).

The plants were grown from seeds in a greenhouse (8/16 h night/day; $23 / 28^{\circ} \mathrm{C}$ night/day, light intensity $\left.300-400 \mathrm{mM} / \mathrm{m}^{2}\right)$. Genomic DNA was isolated from leaves using ZR-96 Plant/Seed DNA Kit (Zymo research, Irvine, USA). Five weeks after planting in the greenhouse, as fruit formation started, tissue samples were collected simultaneously from each plant, including leaves, young buds, open flowers, and immature green fruits, at 9.00-12.00 a.m. The sampled material was immediately frozen and ground in liquid nitrogen. Total RNA was isolated using a RNeasy 
Plant Mini Kit (QIAGEN, Hilden, Germany) and used for cDNA synthesis with a GoScript kit (Promega, Madison, USA).

Specific primers, sYB3F (5'-AATCAAATCAATCACAAAARCAG-3') and sYB3R (5'-CACATTAATTGGTTAGACACTTA-3'), were designed based on the complete YABBY3 gene sequence of $S$. lycopersicum (GeneID: 101247051) and S. pennellii (GeneID: 107026918) for an amplification of the full-length copies of this gene in the examined species. Additional internal primers, sYB3ex2R (5'-ATTAGTGCAGTGTCCACATC-3') and sYB3ex4R (5'-TTGATGAATCGGTTGTAAGC-3'), were designed for sequencing. The genes were amplified using LongAmp ${ }^{\circledR}$ polymerase Hot Start Taq DNA Polymerase (USA) under the following conditions: initial denaturation $\left(10 \mathrm{~min}, 94^{\circ} \mathrm{C}\right) ; 35$ cycles of denaturation $\left(30 \mathrm{sec}, 94^{\circ} \mathrm{C}\right)$; annealing $\left(30 \mathrm{sec}, 58^{\circ} \mathrm{C}\right)$ and elongation $\left(4 \mathrm{~min}, 65^{\circ} \mathrm{C}\right)$; and final elongation $(10 \mathrm{~min}$, $65^{\circ} \mathrm{C}$ ). PCR fragments were purified using a QIAEX ${ }^{\circledR}$ II Gel Extraction kit (QIAGEN, Hilden, Germany), cloned into the plasmid vector pGEMT-easy (Promega, Madison, USA), and sequenced using the BigDye system and an Applied Biosystems 3730 DNA analyzer (Applied Biosystems, Waltham, United States; Core Facility "Bioengineering").

The obtained sequences were aligned and analyzed using the MEGA 7.0 [33]. The comparative analysis was carried out using known YABBY3 complete sequences of two tomato species, $S$. lycopersicum cv. Heinz (GeneID:101247051) and $S$. pennellii (GeneID: 107026918), potato $S$. tuberosum (GeneID: 102577797), and $A$. thaliana (GeneID : 827 914). The positions of nucleotide and amino acid substitutions were determined in comparison with the $S$. lycopersicum cv. Heinz YABBY3 (GeneID: 101247051). The structural domains of YABBY 3 orthologs were determined using NCBI-CDD (http://www.ncbi.nlm.nih.gov/Structure/cdd/wrpsb. cgi) and published data [27, 28]. Known sequences of YABBY genes, cDNAs, and the proteins of $S$. lycopersicum (SlYABBY1 (XM_004229745), SlYABBY2 (XM_004241308), SlYABBY3 (XM_004245689), SlYABBY5a (XM_004242730), SlYABBY5b (XM_004251674), SlFAS (NM_001247461), SlINO (XM_004239291), SlCRCa (XM_004238984), SlCRCb (XM_004228801)), and A. thaliana (AtYABBY1 (AF136538), AtYABBY2 (AF136539), AtYABBY 3 (AF136540), AtYABBY5 (NM_179750), AtINO (AF195047), AtCRC (AF132606)) were subjected to a phylogenetic analysis performed using the MEGA 7.0 Maximum Likelihood method (ML), preassigned by the Modeltest program. The possible effects of the amino acid substitutions on the protein structure and function were assessed using the Grantham matrix [34] and PROVEAN [35]. The three-dimensional protein structure was analyzed us- ing the Phyre2 program [36] and visualized by Chimera 1.11.2 (http://www.cgl.ucsf.edu/chimera/).

YABBY 3-orthologous genes expression was determined in young leaves, young buds, open flowers, and green immature fruits by quantitative real-time PCR (qRT-PCR) using the Reaction mixture for qRT-PCR in the presence of SYBR GreenI and a ROX kit (Syntol, Moscow, Russia) on a CFX96 Real-Time PCR Detection System (Bio-Rad Laboratories, Hercules, USA). qRTPCR was carried out using a gene-specific primer pair: tY3rt1F (5'-GTCACACTTACTTCTCTCCTTCAC-3') and tY3rtR (5'-CAGGAGGTCTGTTAACAACGG-3'). The reactions were carried out in two biological and three technical replicates under the following conditions: $95^{\circ} \mathrm{C}-5 \mathrm{~min} ; 40$ cycles $\left(95^{\circ} \mathrm{C}-15 \mathrm{sec}, 62^{\circ} \mathrm{C}-\right.$ $50 \mathrm{sec}$ ). The relative expression level was assessed using the $C A C$ gene as a reference [37]. The statistical analysis was performed using GraphPad Prism v. 7.02, including the assessment of the statistical significance of the expression differences in various organs of each analyzed tomato species using the unpaired t-test with Welch's correction (Table 3).

\section{RESULTS AND DISCUSSION}

Complete sequences of the YABBY3-orthologous genes were determined in 13 accessions of 11 tomato species (Solanum section Lycopersicon). The comparative analysis of these sequences showed that they are highly homologous (95-99\% similarity) to the known tomato YABBY3 gene (ID: 101247051). The total length of the gene varied from $2622 \mathrm{bp}$ in $S$. neorickii to $2713 \mathrm{bp}$ in $S$. cheesmaniae. The genes were composed of seven exons and six introns (Table 2) and included sequences that encoded the conserved HMG-like YABBY (125-176 aa) and the Cys2Cys2-zinc-finger (18-62 aa) domains (Fig. 1).

In the 9 analyzed accessions, including all red-fruited and three green-fruited (S. chmielewskii, S. chilense, and $S$. habrochaites) species, YABBY $3 \mathrm{cDNA}$ was $651 \mathrm{bp}$ (Table 2). In $S$. neorickii, cDNA was 654 bp due to TCA duplication in the second exon (N66_H67insH in amino acid sequence). In $S$. arcanum, $S$. corneliomulleri, $S$. peruvianum, and $S$. peruvianum var. dentatum, it was $660 \mathrm{bp}$ due to $9 \mathrm{bp}$ insertion in the first exon (P17_S18insPPP). In $S$. pennellii, which is known to be the most ancient species [32], cDNA of $645 \mathrm{bp}$ was due to $6 \mathrm{bp}$ deletion in the second exon (H67del, H68del). Accordingly, the length of the YABBY3 orthologs was 217 aa (S. neorickii), 219 aa (S. arcanum, $S$. corneliomulleri, $S$. peruvianum, and $S$. peruvianum var. dentatum), and 216 aa (other accessions). Interestingly, among the previously described conserved YABBY1/3-characteristic motifs, Solanum YABBY3 orthologs included the clade-specific motifs FIL-A, -D, 


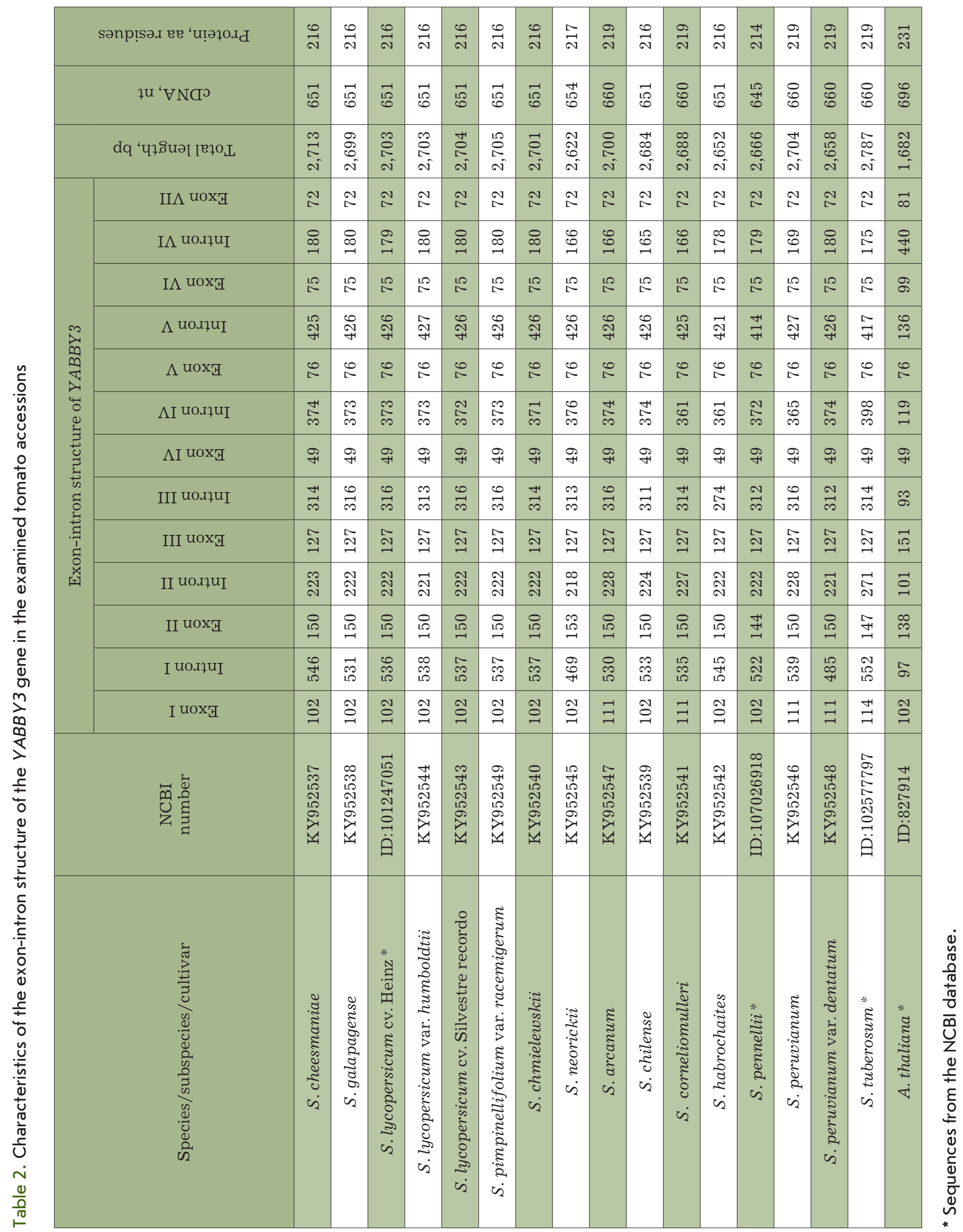


-E, and -G, but no FIL-B and -C, which are usually localized in the inter-domain region [12] (Fig. 1).

When compared with the previously characterized S. lycopersicum cv. Heinz YABBY3 (ID: 101247051), in the YABBY 3 genes of the analyzed accessions, 317 variable sites, mostly localized in introns, were revealed. In the exons, 24 substitutions were detected, and 8 of them were nonsynonymous. Substitutions detected in cDNA were localized mainly in the sequence encoding the inter-domain region and at the 3 '-terminus. In the region encoding the zinc-finger domain, only one substitution was detected: A59G transition in S. galapagense, which leads to a glutamine on arginine substitution, Q20R (Fig. 1). The sequence encoding the YABBY-domain revealed five nucleotide substitutions, and only one of them, A434G transition in S. peruvianum var. dentatum (3966), leads to a glutamic acid on glycine substitution, E145G (Fig. 1).

In YABBY 3 proteins, 4 out of 11 aa substitutions (S64C, Y76C, D116G, and E145G) (Fig. 1) are considered to be radical (physicochemical distance according to Grantham's matrix <57.9). At the same time, an assessment using PROVEAN, generalizing known algorithms for a charge of aa substitutions and indels, revealed only one radical substitution (E145G in the $S$. peruvianum var. dentatum YABBY-domain), whereas the other substitutions, deletions, and insertions were rated as neutral. The possible effect of substitutions on the protein function needs further experimental analysis.

Modeling (Phyre2) of the YABBY3 three-dimensional structures showed a disordered organization of more than $60 \%$ of the sequence, while $29 \%$ were predicted with a confidence of more than $90 \%$ based on the known HMG-like protein structures (PDB: d1qrva, d1k99a etc.). The reliably predicted sequence was represented by a HMG-like YABBY domain [10] consisting of two $\alpha$-helices connected by a loop (helix-loop-helix) (Fig. 2). The HMG-domain presumably binds to the DNA minor groove and bends the double helix at that point [38].

The phylogenetic analysis showed that all known $S$. lycopersicum YABBY genes are clustered with the corresponding A. thaliana orthologs (Fig. 3). On the cDNA-based dendrogram, YABBY genes formed four sub-clusters: YAB1/3 (YABBY1- and YABBY3-like genes); YAB2/5 (YABBY2-, YABBY5-, and FAS-like genes); CRC (CRC-like genes); and INO (INO-like genes) (Fig. 3A). The clusters resulting from the analysis of the amino acid sequences (Fig. 3B) were similar to those described above, except for YABBY2 and YABBY5, which formed separate sub-clusters corresponding to the previously proposed classification of the YABBY family into five subfamilies [10,
Table 3. The ANOVA analysis of $Y A B B Y 3$ gene expression in tomato species using Welch's t-test.

\begin{tabular}{|c|c|c|c|}
\hline \multicolumn{4}{|c|}{ S. lycopersicum cv. Silvestre recordo } \\
\hline & Leaf & Bud & Flower \\
\hline Bud & 0.0012 & & \\
\hline Flower & 0.6189 & 0.0007 & \\
\hline Fruit & $<0.0001$ & $<0.0001$ & $<0.0001$ \\
\hline \multicolumn{4}{|c|}{ S. chmielewskii } \\
\hline & Leaf & Bud & Flower \\
\hline Bud & 0.0242 & & \\
\hline Flower & 0.1117 & 0.5025 & \\
\hline Fruit & $<0.0001$ & $<0.0001$ & $<0.0001$ \\
\hline \multicolumn{4}{|c|}{ S. peruvianum var. dentatum } \\
\hline & Leaf & Bud & Flower \\
\hline Bud & $<0.0001$ & & \\
\hline Flower & 0.1014 & $<0.0001$ & \\
\hline Fruit & $<0.0001$ & 0.3049 & $<0.0001$ \\
\hline \multicolumn{4}{|c|}{ S. habrochaites } \\
\hline & Leaf & Bud & Flower \\
\hline Bud & $<0.0001$ & & \\
\hline Flower & $<0.0001$ & $<0.0001$ & \\
\hline Fruit & $<0.0001$ & $<0.0001$ & $<0.0001$ \\
\hline
\end{tabular}

${ }^{*} p$-values $<0.05$ are considered as significant.

$23]$. The phylogenetic analysis based on the $Y A B B Y 3$ genomic sequences clustered the analyzed tomato accessions into two groups with a branch of the most ancient $S$. pennellii and potato $S$. tuberosum (Fig. 4). The results generally agreed with the tomato division into green-fruited and red-fruited, as well as self-compatible and self-incompatible, groups. At the same time, two self-compatible green-fruited species, $S$. chmielewskii and $S$. neorickii, fell into opposing clusters, which apparently corresponds to an evolutionary boundary point where red-fruited self-compatible species originated from green-fruited self-incompatible ones.

The YABBY genes expression in angiosperms suggests that $Y A B B Y 1 / 3$ genes preserved their ancient expression pattern [12], transcribing in the abaxial portion of the primordia of all aboveground lateral organs (except for ovules) [25, 41]. This is confirmed by our data on YABBY3 expression in the vegetative and reproductive organs of $S$. chmielewskii, $S$. lycopersicum cv. Silvestre recordo, $S$. habrochaites, and $S$. peruvianum var. dentatum. In $S$. habrochaites, gene expression in 


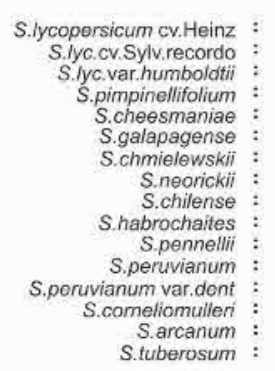

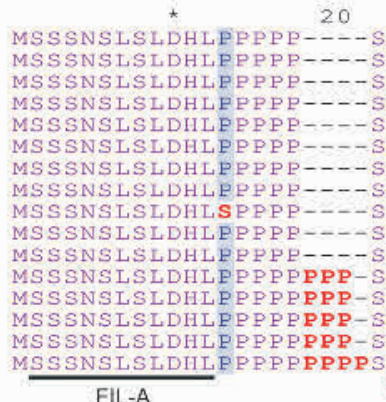

FIL-A

80

20

* 40 * 40.60

Q

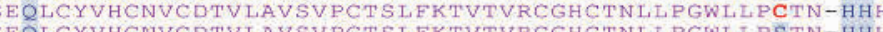
Q

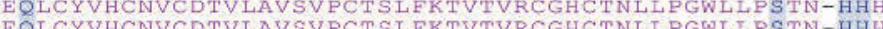
ERLCYVHCNVCDTVIAVSVPCTSIFKTVTVRCGHCTNLLPGWLLPSTN-HHH SEOLCYVHCNVCDTVLAVSVPCTSLFKTVTVRCGHCTNLLPGWLLPSTN-HHH SEOLCYVHCNVCDTVLAVSVPCT SLFKTVTVRCGHCTNLLPGWLIPSTNHHHH EOLCYVHCNVCDTVLAVSVPCTSLFKTVTVRCGHCTNLLPGWLLPSTN-HHH EOLCYVHCNVCDTVLAVSVPCTSLFKTVTVRCGHCTNLLPGWLLPSTN-HHH DEY EOLCYVHCNVCDTVLAVSVPCTSLFKTVTVRCGHCTNLLPGWLLPSTN-HHH EQLCYVHCNVCDTVLAVSVPCTSLFKTVTVRCGHCTNLLPGWLIPSTN-HHH EQLCYVHCNVCDTVLAVSVPCTSLFKTVTVRCGHCTNLLPGWLLPSTN-HHH EQLCYVHCNVCDTVLAVSVPCTSLFKTVTVRCGHCTNLLPGWLLPSTN-HHH
EQLCYVHCNVCDTVLAVSVPCTSLFKTVTVRCGHCTNLLPGWLISTN--HH EQLCYVHCNVCDTVLAVSVPCTSLFKTVTVRCGHCTNLLPGWLLP
EqLCYVHCNVCDTVLAVSVPCTSLFKTVTVRCGHCTNLIPGWLL

S.lycopersicum cv.Heinz :

S.lyc.cv.Sylv.recordo
S.lyc. var humboldtii 100 120 140

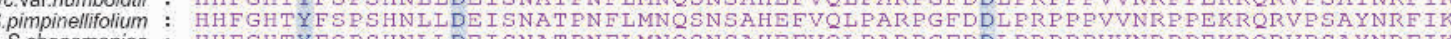

S.cheesmaniae : HHFGHTYF SPSHNLLDEISNATPNFLMNQSNSAHEFVQLPARPGEDDLPRPPPVVNRPPEKRQRVPSAYNRFIK

S.galapagense : HHFGHTYF SPSHNLIDEISNATPNFLMNQSNSAHEFVQLPARPGEDDLPRP PPVVNRP PEKRQRVPSAYNREIK

S.chmielewskii : HHFGHTYFSPSHNLLDEISNATPNFLMNQSNSAHEFVQLPARPGEDDLPRPPPVVNRPPERRQRVPSAYNRFIK S.neorickii : HHFGHTYFSPSHNLLDET SNATPNFLMNQSNSAHEFVQTPARPGEDDLPRPPPVVNRPPERRQRVRSAYNRFTK S.chilense : HHFGHTYFSPSHNLLDETSNATPNFLMNQSNSAHEFVQLPARPGFDDI,PRPPPVVNRPPERRQRVPSAYNRFTK

S.habrochaites : HHFGHTYFSPSHNLLDEISNATPNFLMNQSNSAHEFVQLPARPGEDDLPRPPPVVNRPPEKRQRVPSAYNRFIK S.pennellii : HHFGHTYFSPSHNLLDEI SNA T N N LMNQSNSAHEFVQLEARPGEDDLPRPPPVVNRPPE KRQRVPSAYNRFIK S.peruvianum : HHFGHTCFSPSHNILDETSNATPNFLMNQSNSAHEFVQLPARPGFDDLPRPPPVVNRPPEKRQRVPSAYNRFTK vianum var.dent : HHFGHTYFSPSHNLIDET SNAT PNFLMNQSNSAHEFVQT.PARPGEDDLPRPPPVVNRPPEKRQRVPSAYNRFTK S.comeliomulleri : HHFGHTYFSPSHNLLDEISNATPNFLMNQSNSAHEFVQLPARPGEDDLPRPPPVVNRPPEKRQRVPSAYNRF IK S.arcanUm : HHFGHTYFSPSHNLIDET SNATPNFLMNQSNSAHEFVQLPARPGFDDLPRPPPVVINRPPEKRQRVPSAYNRFTR S.tuberosum :

$$
\text { FIL-D }
$$

VNRPPEKRORVPSAYNRFIK

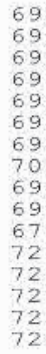
EETQRIKAGNPDTSHREAFSAAAKNWAHFPHI 160

180 200 220

S.lycopersicum cv.Heinz :
S.lyc.cv.Sylv.recordo :
S.lyc.var.humboldtii :
S.pimpinellifolium
S.cheesmaniae
S.galapagense
S.chmielewskii
S.neorickii :
S.chilense :
S.habrochaites :
S.pennellii :
S.peruvianum :
S.peruvianum var.dent :
S.comeliomulier :
S.arcanum :
S.tuberosum : EETQRIKAGNPDTSHREAFSAAAKNWAHFPHI 160 QQD TKDGLFNTSANVSVSPY GETORTKAGNPDTSHREAFSAAAKNWAHFPHTOFTMPDOTUKRTNUROODGEDVTTKDGIFNTSANUSVSPY EEIQRIKAGNPDI SHREAF SAAAKNWAHFPHIQFGLMPDQTVKRTNVRQQDGFDVITKDGLFNTSANVSVSPY EEIQRIKAGNPDISHREAFSAAAKNWAHFPHIQFGIMPDQTVKRTNVRQQDGEDVLTKDGLFNTSANVSVSPY EEIORIKAGNPDISHREAFSAAAKNWAHEPHIQFGIMPDQTVKRTNVRQQDGEDVITKDGIFNTSANVSVSPY EEIQRIKAGNPDISHREAFSAAAKNWAHFPHIQFGLMPDQTVKRTNVRQQDGEDVLTKDGLFNTSANVSVSPY EEIQRIKAGNPDISHREA S SAAAKNWAHFPHIQFGLMPDQTVKRTNVRQQDGEDVLTKDGLFNTSANVSVSPY EEIQRI KAGNPDISHREA F SAAAKNWAHFPHIQFG IMPDQTVKRTNVRQQDGEDVLTKDGLFNTSANVSVSPY EEIORIKAGNPDISHREAESAAAKNWAHFPHIOFGLMPDOTVKRTNVROQDGEDVITKDGLENTSANVSVSPY EEIORIKAGNPDI SHREAESAAAKNWAHFPHIOFGIMPDOTVKRTNVROODGEDVLTKDGLENTSANVSVSPY EGIORIKAGNPDISHREAFSAAAKNWAHFPHIOFGLMPDOTVKRTNVROQDGEDVITKDGLFNTSANVSVSPY EGIORTKAGNPDISHREAFSAAAKNWAHFPHIOFGIMPDOTVKRTNVROODGEDVLTKDGLFNTSANVSVSPY EEIORIKAGNPDISHREAF SAAAKNWAHFPHIOFGIMPDOTVKRTNVROODGEDVLTKDGLENTSANVSVSPY EEIQRIKAGNPDISHREAESAAAKNWAHFPHIQFGLMPDQTVKRTNVRQQDGEDVLMKDGLFNTSANVSVSPY EOIQRIKAGNPDISHREAFSAAAKNWAHFPHI

FIL-E

FIL-F

FIL-G

Fig. 1. Alignment of YABBY3 amino acid sequences from accessions of tomato and potato (S. tuberosum) species. The Zinc-finger and YABBY domains are indicated by blue and green letters, respectively, under alignment. Indels and substitutions are highlighted in red. Conserved motifs specific to YABBY1/YABBY3 clade are underlined and named

leaves is somewhat higher than that in flowers, while the other three species have no statistically significant differences in YABBY3 expression levels in leaves and flowers (Fig. 5, Tab. 3). At the same time, almost no YABBY 3 expression was detected in the fruits of the studied species, except for $S$. peruvianum var. dentatum (Fig. 5). These four species were selected for expression analysis, since they belong to four groups that are evolutionarily distant from each other. $S$. lycopersicum is a red-fruited, self-compatible species of relatively recent origin; $S$. chmielewskii is a green-fruited, but self-compatible, species, and its position on the evolutionary tree is between red-fruited self-compatible and green-fruited self-incompatible species; $S$. peruvianum is a representative of the green-fruited self-incompatible species; and, finally, $S$. habrochaites (green-fruited, self-incompatible) is considered as one of the most ancient tomato species [32]. The YABBY 3 expression pattern in $S$. peruvianum var. dentatum is somewhat different from that in other analyzed accessions, although the reason for the low-level expression in buds is not fully understood (Fig. 5). In the analyzed organs of $S$. habrochaites, the YABBY 3 expression dynamics is similar, but the transcription level is almost twice lower than that in $S$. lycopersicum and $S$. chmielewskii. In general, the identified YABBY3 expression patterns in S. lycopersicum, $S$. chmielewskii, and $S$. habrochaites were similar to those in $S$. pimpinellifolium, wherein the YABBY 3 expression level is maximal in young buds and decreases along with flower-to-fruit development [30].

It has been shown that, in A. thaliana, both the YABBY 3 constitutive expression and its knockout lead to an abnormal development of leaves and flowers due 
R 126



Fig. 2. S. lycopersicum cv. Heinz YABBY3 (XM_004245689) tertiary structure (Phyre2): $\alpha$-helices forming the YABBY domain are indicated by arrows

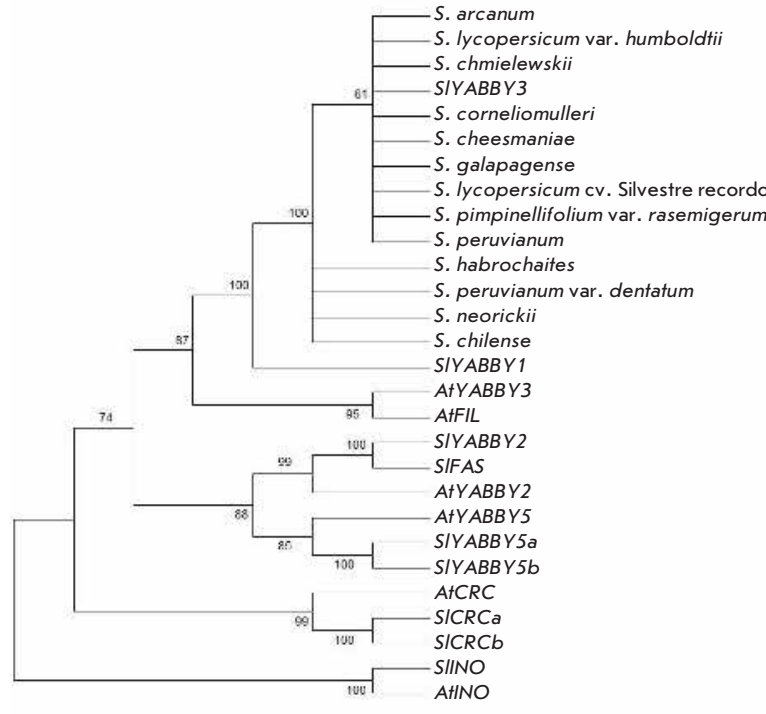

$A$
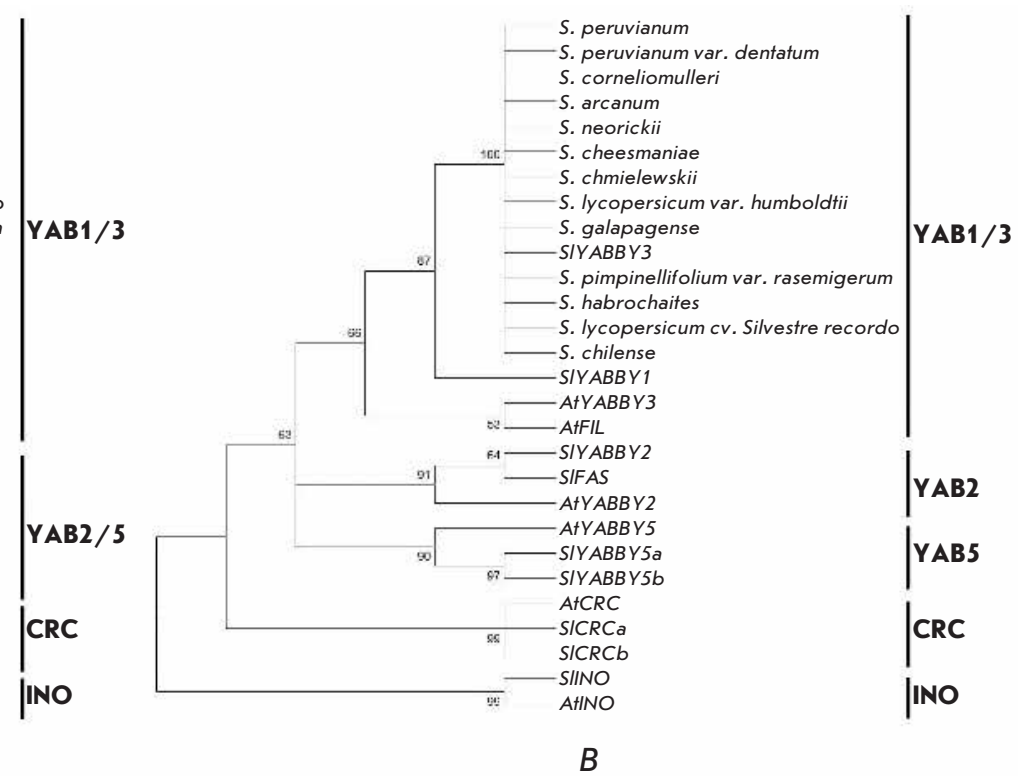

Fig. 3. Phylogeny of YABBY genes in S. lycopersicum (SI) and A. thaliana (At) based on cDNA (A) and amino acid sequences (B) (MEGA7.0, ML method; (A) - Hasegawa-Kishino-Yano model [39]+ Gamma distributed with invariant sites), (B) - Dayhoff model [40]+ Gamma distributed) 


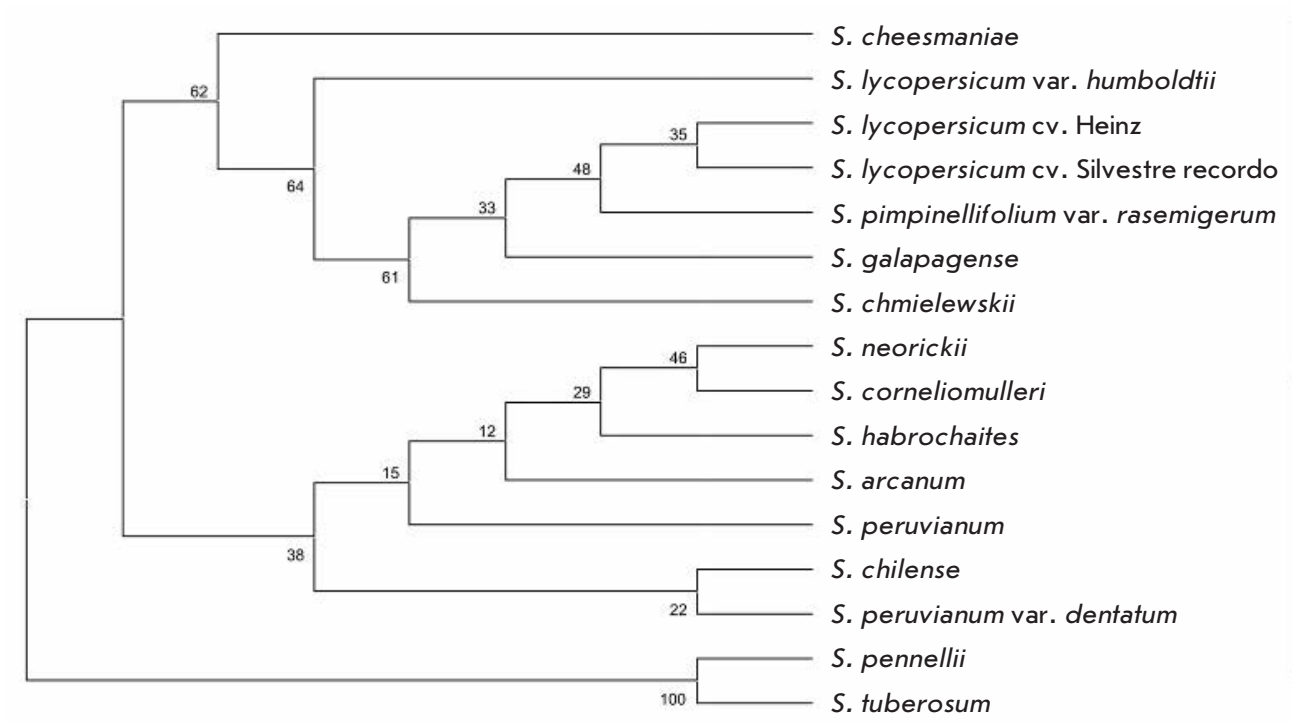

Fig. 4. Phylogenetic tree based on $Y A B B Y 3$ genomic

$\stackrel{4}{\alpha}$ sequences of the accessions of cultivated and wild tomato species and rooted with $S$. tuberosum YABB Y3 (MEGA7.0, $M L$ method, model $H K Y+G+I) \cdot R F$

$\perp$ - red-fruited accessions; GF - greenfruited accessions; SC - self-compatible accessions; SI - selfincompatible accessions

Fig. 5. Relative $Y A B B Y 3$ expression in the leaves (L), young buds (B), opened flowers (FI), and green immature fruits (Fr) of four tomato accessions

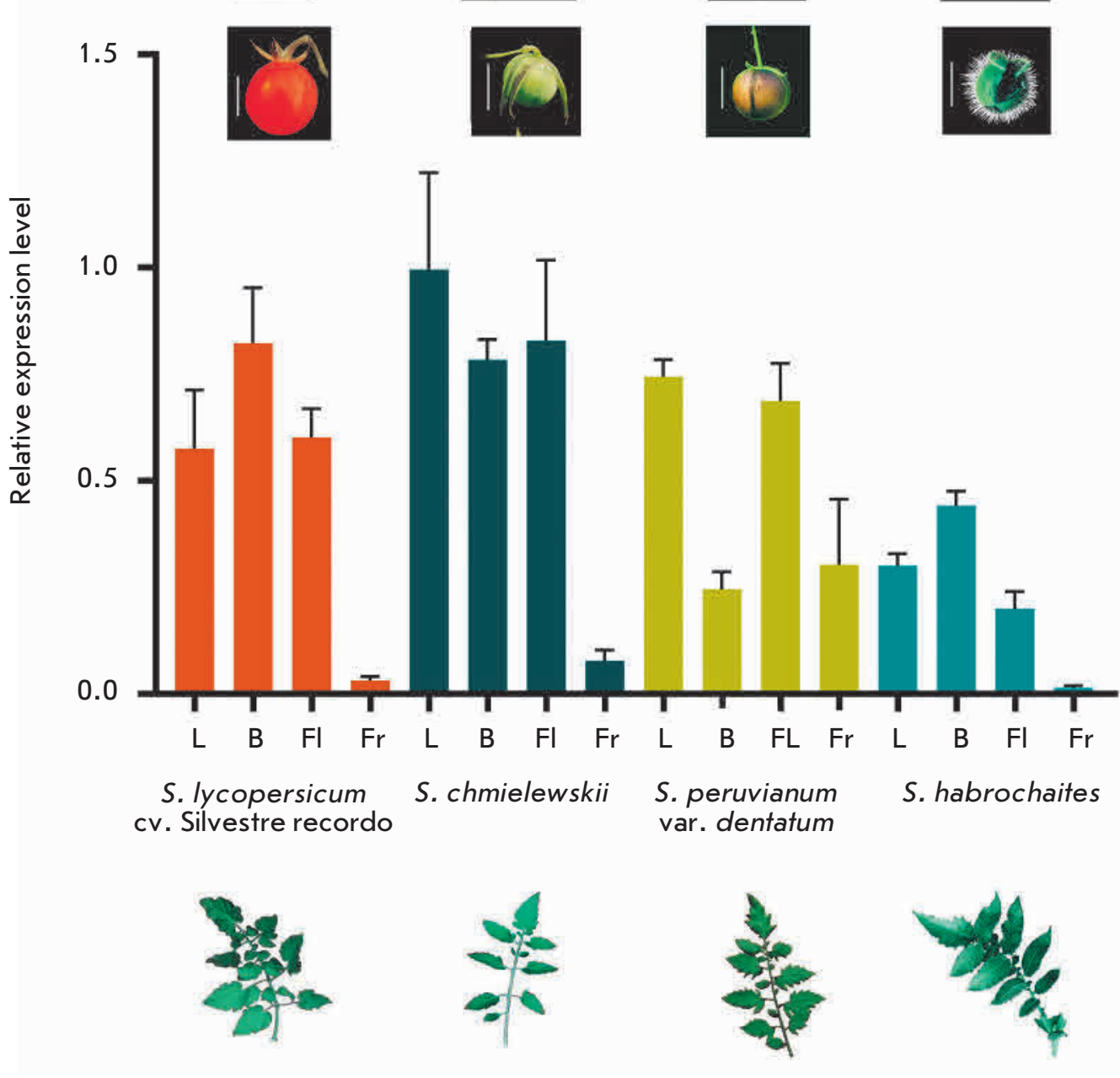


to the lack of polar differentiation in the organs [18]. The variability of this gene expression level can also affect the organ structure and morphophysiology; in particular, the leaves, flowers, and fruits of the analyzed tomato accessions. Significant levels of gene expression in $S$. peruvianum var. dentatum fruits may be indicative of a possible preservation of abaxial tissue identity in the fruit skin.

\section{CONCLUSION}

In this study, YABBY3-orthologous genes were detected in 13 accessions of cultivated and wild tomato species. These genes encode transcription factors that play a key role in determining the abaxial-adaxial asymme-

REFERENCES

1. Albert E.V., Ezhova T.A. // Russian Journal of Genetics. 2013. V. 49. № 2. P. 127-140.

2. Lutova L.A., Dodueva I.E., Lebedeva M.A., Tvorogova V.E. // Russian Journal of Genetics. 2015. V. 51. № 5. P. 449-466.

3. Castrillo G., Turck F., Leveugle M., Lecharny A., Carbonero P., Coupland G., Paz-Ares J., Oñate-Sánchez L. // PLoS One. 2011. V. 6. № 6. e21524.

4. Yang C., Ma Y., Li J. // J. Exp. Bot. 2016. V. 67. № 18. P. 5545-5556.

5. Gramzow L., Ritz M.S., Theissen G. // Trends Genet. 2010.

V. 26. № 4. P. $149-153$.

6. Melzer R., Theissen G. // Methods Mol. Biol. 2011. V. 754.

P. 3-18.

7. Sarojam R., Sapp P.J., Goldshmidt A., Efroni I., Floyd S.K., Eshed Y., Bowman J.L. // Plant Cell. 2010. V. 22. № 7. P. 2113-2130.

8. Floyd S.K., Bowman J.L. // Int. J. Plant Sci. 2007. V. 168. № 1. P. 1-35.

9. Rensing S.A., Lang D., Zimmer A.D., Terry A., Salamov A., Shapiro H., Nishiyama T., Perroud P.F., Lindquist E.A., Kamisugi Y., et al. // Science. 2008. V. 319. № 5859. P. 64-69. 10. Finet C., Floyd S.K., Conway S.J., Zhong B., Scutt C.P., Bowman J.L. // Evol. Dev. 2016. V. 18. № 2. P. 116-126.

11. Yamada T., Yokota S., Hirayama Y., Imaichi R., Kato M.,

Gasser C.S. // Plant J. 2011. V. 67. № 1. P. 26-36.

12. Bartholmes C., Hidalgo O., Gleissberg S. // Plant Biol (Stuttg.). 2012. V. 14. № 1. P. 11-23.

13. Meyerowitz E.M. // Cell. 1997. V. 88. № 3. P. 299-308.

14. Bowman J.L., Eshed Y., Baum S.F. // Trends Genet. 2002.

V. 18. № 3. P. 134-141.

15. de Almeida A.M.R., Yockteng R., Schnable J., Alvarez-

Buylla E.R., Freeling M., Specht C.D. // Sci. Rep. 2014. V. 4.

Article number 6194.

16. Morioka K., Yockteng R., Almeida A.M., Specht C.D. //

Front Plant Sci. 2015. V. 6. Article 1106.

17. Kelley D.R., Skinner D.J., Gasser C.S. // Plant J. 2009.

V. 57. № 6. P. 1054-1064.

18. Siegfried K.R., Eshed Y., Baum S.F., Otsuga D., Drews G.N., Bowman J.L. // Development. 1999. № 126. P. 4117-4128.

19. Villanueva J.M., Broadhvest J., Hauser B.A., Meister R.J., Schneitz K., Gasser C.S. // Genes Dev. 1999. V. 13. № 23. P. 3160-3169.

20. Fourquin C., Vinauger-Douard M., Fogliani B., Dumas C., Scutt C.P. // Proc. Natl. Acad. Sci. USA. 2005. V. 102. № 12. P. 4649-4654. try of all aboveground plant lateral organs. The structure of $Y A B B Y 3$ genes and the encoded proteins is similar to that of the previously characterized members of the YABBY family. A phylogenetic and expression analysis confirmed that the identified genes belong to the $Y A B B Y 1 / 3$ subfamily and may have conserved functions in different tomato species.

This work was supported by the Russian Science

Foundation (grant No. 16-16-10022), and was done with the use of the experimental climate control facility and Core Facility "Bioengineering" (Federal Research Center of Biotechnology, Russian Academy of Sciences).

21. Lee J.Y., Baum S.F., Alvarez J., Patel A., Chitwood D.H., Bowman J.L. // Plant Cell. 2005. V. 17. № 1. P. 25-36. 22. Stahle M.I., Kuehlich J., Staron L., von Arnim A.G., Golz J.F. // Plant Cell. 2009. V. 21. № 10. P. 3105-3118.

23. Lee J.Y., Baum S.F., Oh S.H., Jiang C.Z., Chen J.C., Bowman J.L. // Development. 2005. № 132. P. 5021-5032.

24. Sawa S., Ito T., Shimura Y., Okada K. // Plant Cell. 1999. V. 11. № 1. P. $69-86$.

25. Sawa S., Watanabe K., Goto K., Kanaya E., Morita E.H., Okada K. // Genes Dev. 1999. V. 13. № 9. P. 1079-1088.

26. Chen Q., Atkinson A., Otsuga D., Christensen T., Reynolds L., Drews G.N. // Development. 1999. № 126. P. 2715-2726.

27. Bowman J.L. // Curr. Opin. Plant Biol. 2000. V. 3. P. 17-22.

28. Kanaya E., Nakajima N., Okada K. // J. Biol. Chem. 2002. V. 277. № 14. P. 11957-11964.

29. Toriba T., Harada K., Takamura A., Nakamura H., Ichikawa H., Suzaki T., Hirano H.Y. // Mol. Genet. Genomics. 2007. V. 277. № 5. P. 457-468.

30. Huang Z., van Houten J., Gonzalez G., Xiao H., van der Knaap E. // Mol. Genet. Genomics. 2013. V. 288. № 3-4. P. 111-129.

31. Han H.Q., Liu Y., Jiang M.M., Ge H.Y., Chen H.Y. // Genet. Mol. Res. 2015. V. 14. № 2. P. 7079-7091.

32. Peralta I.E., Spooner D.M., Knapp S. // Systematic Botany Monographs Am. Soc. Plant Taxonomists, USA. 2008. V. 84.186 p.

33. Kumar S., Stecher G., Tamura K. // Mol. Biol. Evol. 2016. V. 33. № 7. P. $1870-1874$.

34. Grantham R. // Science. 1974. V. 185. P. 862-864.

35. Choi Y., Sims G.E., Murphy S., Miller J.R., Chan A.P. //

PLoS One. 2012. V. 7. № 10. e46688.

36. Kelley L.A., Mezulis S., Yates C.M., Wass M.N., Sternberg M.J. // Nat. Protoc. 2015. V. 10. № 6. P. 845-858.

37. Expósito-Rodríguez M., Borges A.A., Borges-Pérez A., Pérez J.A. // BMC Plant Biol. 2008. V. 8. № 131. P. 1-12.

38. Bowman J.L., Smyth D.R. // Development. 1999. № 126. P. 2387-2396.

39. Hasegawa M., Kishino H., Yano T. // J. Mol. Evol. 1985.

V. 22. № 2. P. $160-174$.

40. Dayhoff M.O., Schwartz R.M., Orcutt B.C. // Atlas Protein Sequence and Structure. 1978. V. 5. P. 345-352.

41. Golz J.F., Roccaro M., Kuzoff R., Hudson A. // Development. 2004. № 131. P. 3661-3670. 